\title{
The value of cardiopulmonary exercise testing in the diagnosis of pulmonary hypertension
}

\author{
Qin Luo ${ }^{1 \#}$, Xue Yu ${ }^{2 \#}$, Zhihui Zhao ${ }^{1}$, Qing Zhao ${ }^{1}$, Xiuping Ma ${ }^{1}$, Qi Jin ${ }^{1}$, Lu Yan ${ }^{1}$, Yi Zhang ${ }^{1}$, Zhihong Liu ${ }^{1}$ \\ ${ }^{1}$ Center for Pulmonary Vascular Diseases, Fuwai Hospital, National Center for Cardiovascular Diseases, Chinese Academy of Medical Sciences and \\ Peking Union Medical College, Beijing, China; ${ }^{2}$ Department of Cardiology, Qingdao Municipal Hospital, Qingdao, China \\ Contributions: (I) Conception and design: Q Luo, X Yu; (II) Administrative support: Q Zhao, X Ma; (III) Provision of study materials or patients: Z \\ Liu, Z Zhao; (IV) Collection and assembly of data: X Yu, Q Jin, L Yan, Y Zhang; (V) Data analysis and interpretation: X Yu; (VI) Manuscript writing: \\ All authors; (VII) Final approval of manuscript: All authors. \\ "These authors contributed equally to this work. \\ Correspondence to: Zhihong Liu. Center for Pulmonary Vascular Diseases, Fuwai Hospital, National Center for Cardiovascular Diseases, Chinese \\ Academy of Medical Sciences and Peking Union Medical College, No.167 Beilishi Rd, Xicheng District, Beijing 100037, China. \\ Email: zhihongliufuwai@163.com.
}

Background: Cardiopulmonary exercise testing (CPET) continuously analyzes the gas exchange of patients during rest, exercise, recovery, and simultaneously records the response of the cardiopulmonary system. This study aimed to observe the characteristics of CPET in patients with pulmonary hypertension $(\mathrm{PH})$ and to explore the cutoff value of CPET variables in detecting PH. The diagnostic value of CPET was also investigated in a subgroup of patients who had an incorrect or missed diagnosis of PH by echocardiography.

Methods: Treatment-naïve patients with suspected PH who were admitted to Fuwai Hospital from January 2017 to August 2018 were consecutively enrolled. The gold standard criterion for PH was defined as mean pulmonary artery pressure $(\mathrm{mPAP}) \geq 25 \mathrm{mmHg}$ at rest, measured by right heart catheterization. General clinical materials, echocardiography, hemodynamics, and CPET data of the patients were collected and compared between groups. Logistic regression analyses were performed to explore the CPET variables that were independently associated with PH. To further validate the value of CPET for diagnosing PH, the CPET cutoff values obtained from receiver operating characteristic (ROC) curve analysis were used in patients who had an incorrect or missed diagnosis by echocardiography.

Results: Five hundred and fifty-nine patients were included in the study. Among them, patients with $\mathrm{PH}$ had significantly poorer CPET variables. Multivariate logistic regression analysis showed that peak work rate $(\mathrm{WR})$, peak oxygen uptake $\left(\mathrm{VO}_{2}\right)$, and end-tidal carbon dioxide partial pressure $\left(\mathrm{PetCO}_{2}\right)$ at the anaerobic threshold (AT) were independently associated with $\mathrm{PH}$ after adjustment for age, sex, and body mass index. The above three CPET variables were all negatively correlated with mPAP. The combined CPET variable including peak WR, peak $\mathrm{VO}_{2}$ and $\mathrm{PetCO}_{2}$ at $\mathrm{AT}$ had the largest area under the ROC curve for the diagnosis of $\mathrm{PH}(0.890,95 \% \mathrm{CI}: 0.852-0.927, \mathrm{P}<0.001)$. The cutoff value was 0.86 , and the sensitivity and specificity were $81.8 \%$ and $86.5 \%$, respectively. Using this cutoff value, $83.7 \%$ of patients who were misdiagnosed and $67.9 \%$ of patients who had a missed diagnosis by echocardiography were identified.

Conclusions: PH patients have decreased cardiopulmonary reserve, lower exercise tolerance, and increased ineffective ventilation. The combination of peak $\mathrm{WR}$, peakVO , and $\mathrm{PetCO}_{2}$ at $\mathrm{AT}$ had increased sensitivity and specificity for the diagnosis of $\mathrm{PH}$, and increased the specificity for identifying patients who had been misdiagnosed as $\mathrm{PH}$ by echocardiography.

Keywords: Cardiopulmonary exercise testing (CPET); pulmonary hypertension (PH); cutoff value; echocardiography

Submitted Feb 27, 2020. Accepted for publication Oct 22, 2020.

doi: $10.21037 /$ jtd-20-1061b

View this article at: http://dx.doi.org/10.21037/jtd-20-1061b

(c) Journal of Thoracic Disease. All rights reserved. 


\section{Introduction}

Pulmonary hypertension (PH) refers to a group of pathophysiological syndromes of multiple etiologies. It is characterized by pulmonary vascular remodeling, which causes pulmonary vascular resistance to progressively increase, leading to right heart failure and death (1). Patients with PH usually complain of dyspnea on exertion-a none specific symptom that easily leads to missed diagnosis and misdiagnosis. At diagnosis, $85 \%$ of high-risk $\mathrm{PH}$ patients are already at an advanced stage of the disease $(2,3)$. Therefore, the screening and timely identification of suspected $\mathrm{PH}$ patients are imperative. Right heart catheterization (RHC) is the gold standard for the diagnosis of $\mathrm{PH}$, but it can also cause complications.

Echocardiography is the most commonly used screening method for $\mathrm{PH}$ in the clinical settings. However, it often leads to the overestimation and underestimation of pulmonary artery systolic pressure (4). Held et al. (5) retrospectively analyzed the echocardiographic data of 42 patients with chronic thromboembolic pulmonary hypertension (CTEPH) and showed that echocardiography detected CTEPH in 29 patients (69\%), while the other 13 patients (31\%) went undiagnosed. The European Society of Cardiology proposed that echocardiography was not suitable for screening patients with mild asymptomatic $\mathrm{PH}$ (6). Therefore, more accurate screening methods need to be found. CPET may improve diagnostic specificity in patients with echocardiography-suspected $\mathrm{PH}$.

In recent years, several studies have confirmed the important role of cardiopulmonary exercise testing (CPET) in PH diagnosis. Woods et al. (7) compared the CPET data of $40 \mathrm{PH}$ patients and 25 healthy controls, and found significantly lower end-tidal carbon dioxide partial pressure $\left(\mathrm{PetCO}_{2}\right)$ and higher minute ventilation (VE)/carbon dioxide output $\left(\mathrm{VCO}_{2}\right)$ in the $\mathrm{PH}$ patients. Meanwhile, the levels of PetCO ${ }_{2}$ and $\mathrm{VE} / \mathrm{VCO}_{2}$ were found to be correlated with the severity of $\mathrm{PH}$. Nishio et al. (8) demonstrated that $\mathrm{PH}$ patients had a decreased peak oxygen uptake $\left(\mathrm{VO}_{2}\right)$ and an increased $\mathrm{VE} / \mathrm{VCO}_{2}$ slope compared with chronic heart failure patients. CPET variables were also shown to be associated with hemodynamic parameters. Thirapatarapong et al. (9) reviewed and analyzed the data on pulmonary function, RHC, and CPET in 98 patients with severe chronic obstructive pulmonary disease. They observed that chronic obstructive pulmonary disease patients with $\mathrm{PH}$ had a significantly reduced peak work rate (WR), peak $\mathrm{VO}_{2}$, and peak oxygen pulse $\left(\mathrm{O}_{2}\right.$ pulse). Moreover, peak $\mathrm{VO}_{2}$ was negatively correlated with mean pulmonary artery pressure (mPAP). Accordingly, CPET is expected to serve as a noninvasive but effective means of identifying pulmonary vasculopathy in $\mathrm{PH}$. In this study, we aimed to explore the value of CPET in the diagnosis of $\mathrm{PH}$.

We present the following article in accordance with the STARD reporting checklist (available at http://dx.doi. org/10.21037/jtd-20-1061b).

\section{Methods}

This single center study was conducted at Fuwai Hospital, National Center for Cardiovascular Diseases in Beijing, China. The study was conducted in accordance with the Declaration of Helsinki (as revised in 2013) and was approved by the Committee Board of the Fuwai Hospital. Informed consent was given by all patients.

\section{Study sample}

Untreated patients with suspected $\mathrm{PH}$ who were admitted to Fuwai Hospital between January 2017 and August 2018 were consecutively included in this study. Patients with any of the following conditions were considered to be suspected PH cases: (I) exertional dyspnea as the chief complaint; (II) P2 enhancement and pathological third heart sound during physical examination; (III) elevated levels of plasma B-type natriuretic peptide or $\mathrm{N}$-terminal prohormone of brain natriuretic peptide (NT-proBNP); (IV) electrocardiogram manifestations, such as right axis deviation, right bundle branch block, and other phenomena, reflecting an increased right heart load; (V) protruding pulmonary artery segment and expanded right heart image from chest X-ray; (VI) reduced pulmonary diffusion capacity; (VII) suspected PH by echocardiography, including tricuspid regurgitation velocity (TRV) $>2.8 \mathrm{~m} / \mathrm{s}$, a widened pulmonary artery, a dilated right heart, and a widened inferior vena cava, etc.; (VIII) patients at high-risk of PH.

All patients were over the age of 18 . Patients with any of the following conditions were excluded: (I) recurrent syncope or massive hemoptysis; (II) neuromuscular disease affecting the 6-minute walk test and CPET; (III) severe arrhythmia requiring intervention; (IV) severe liver and kidney dysfunction; (V) severe anemia (hemoglobin $<90 \mathrm{~g} / \mathrm{L}$ ). Patients who had recently received exercise rehabilitation training were also excluded. 


\section{Echocardiography and RHC}

Patients' echocardiographic and hemodynamic parameters were collected in addition to their age, sex, body mass index (BMI), 6-minute walking distance (6-MWD), World Health Organization functional class (WHO FC), and plasma levels of NT-proBNP. As a screening tool for PH, echocardiography was performed on each patient on the day of admission. Patients who had a TRV $>2.8 \mathrm{~m} / \mathrm{s}$ and other echocardiographic signs such as a widened pulmonary artery, dilated right heart, and widened inferior vena cava were considered to have PH (10). The diastolic left ventricle diameter was measured in the left ventricular long-axis view, and the diastolic right ventricle diameter was measured in the apical four-chamber view. Ejection fraction was assessed using the Simpson biplane method.

The diagnosis of $\mathrm{PH}$ in each patient was confirmed by RHC. As the gold standard for PH diagnosis, RHC was conducted by experienced pulmonary vascular physicians. The hemodynamic parameters obtained by RHC included right atrial pressure, mPAP, total pulmonary resistance, cardiac index, and mixed venous oxygen saturation. As assessed by RHC, $\mathrm{mPAP} \geqslant 25 \mathrm{mmHg}$ at rest was defined as PH (11). Physicians who conducted RHC were blind to the CPET information of the participants.

\section{CPET}

Before RHC, each suspected $\mathrm{PH}$ patient enrolled in this study underwent symptom-limited CPET using the COSMED Quark CPET system. The performers of CPET were blind to the RHC information of the enrolled patients. The following four phases were completed on a cycle ergometer: (I) 3 minutes of rest; (II) 3 minutes of unloaded pedaling at an approximate speed of $60 \mathrm{rpm}$; (III) WR-incremental exercise to achieve maximal tolerance; (IV) 5 minutes of recovery. $\mathrm{VE}, \mathrm{VO}_{2}$, and $\mathrm{VCO}_{2}$ were measured breath-by-breath and were averaged every 10 seconds during the entire process. Meanwhile, the responses of the cardiovascular system including blood pressure, heart rate (HR), and a 12-lead electrocardiogram were recorded.

Peak $\mathrm{VO}_{2}$ was defined as the highest 30 -second average value of $\mathrm{VO}_{2}$ during the final minute of exercise. The anaerobic threshold (AT) was the maximal $\mathrm{VO}_{2}$ before the onset of lactic acidosis, which was determined using the $\mathrm{V}$-slope method. The peak $\mathrm{O}_{2}$ pulse was the ratio of peak $\mathrm{VO}_{2}$ to peak HR. The $\mathrm{VE} / \mathrm{VCO}_{2}$ slope was the linear regression slope of the relation of $\mathrm{VE}$ to $\mathrm{VCO}_{2}$ over the whole exercise period. The oxygen uptake efficiency slope (OUES) was the slope in the following equation: $\mathrm{VO}_{2}=$ OUES $\times \mathrm{VE}+\mathrm{B}$. The peak respiratory exchange ratio (RER) was defined as the ratio of peak $\mathrm{VCO}_{2}$ to peak $\mathrm{VO}_{2}$. Heart rate recovery (HRR) was considered as the maximum HR minus the HR at 2 minutes after peak exercise. Peak circulatory power was defined as the product of peak $\mathrm{VO}_{2}$ and peak systolic blood pressure (SBP). Peak ventilatory power was defined as peak SBP divided by the $\mathrm{VE} / \mathrm{VCO}_{2}$ slope (12). Ventilation efficiency was assessed according to the $\mathrm{VE} / \mathrm{VCO}_{2}$ ratio, $\mathrm{VE} / \mathrm{VCO}_{2}$ slope, and $\mathrm{PetCO}$.

\section{Statistical analysis}

Continuous variables are presented as the mean \pm standard deviation or median (interquartile range), and categorical variables are presented as counts or percentages. To compare the differences between groups, an independent sample $t$-test was used for continuous variables with normal distribution, a non-parametric Kruskal-Wallis test was used for continuous variables with non-normal distribution, and the chi-square test was used for categorical variables. Univariate and multivariate logistic regression analyses were carried out to identify the CPET variables that were independently associated with $\mathrm{PH}$. Furthermore, linear correlation analysis between CPET variables and mPAP was performed. Receiver operating characteristic (ROC) curve analysis was used to determine the cutoff values, sensitivity, and specificity of CPET variables for diagnosing PH. Missing data are processed using weights. $\mathrm{P}<0.05$ was defined as statistically significant. All statistical analyses were carried out with SPSS 22.0 software (SPSS, Inc., Chicago, IL, USA).

\section{Results}

In total, 559 suspected $\mathrm{PH}$ patients without treatment were recruited. Of them, 485 patients were confirmed as $\mathrm{PH}$ by RHC, including 136 patients with congenital heart disease-associated pulmonary arterial hypertension, 117 with idiopathic pulmonary arterial hypertension, 86 with CTEPH, 35 with connective tissue disease-associated pulmonary arterial hypertension, 19 with hypoxia-associated $\mathrm{PH}, 16$ with $\mathrm{PH}$ due to pulmonary vasculitis, 12 with left heart disease-associated $\mathrm{PH}, 8$ with heritable pulmonary arterial hypertension, 7 with pulmonary veno-occlusive disease, and 49 with other subtypes of $\mathrm{PH}$. The participant enrollment and exclusion processes are detailed in Figure 1. 


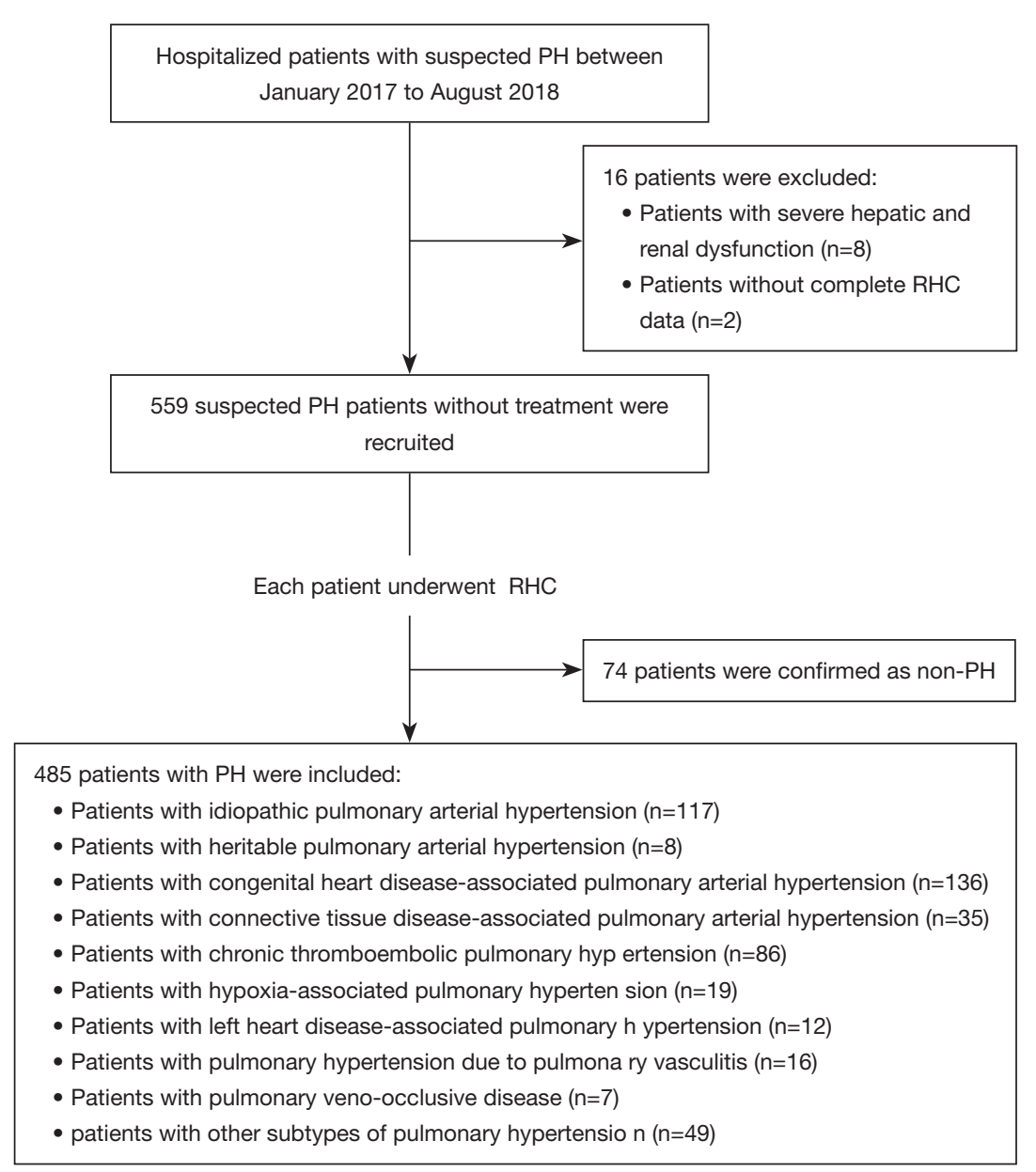

Figure 1 Flow diagram of participant enrollment and exclusion. PH, pulmonary hypertension; RHC, right heart catheterization.

\section{Baseline characteristics of patients}

Baseline characteristics were compared between patients with and without $\mathrm{PH}$. $\mathrm{PH}$ patients were younger $(42 \pm 14$ vs. $50 \pm 14$ years, $\mathrm{P}<0.001)$ and had a lower BMI $(22.6 \pm 3.9$ vs. $\left.23.8 \pm 3.6 \mathrm{~kg} \cdot \mathrm{m}^{-2}, \mathrm{P}=0.005\right)$, a shorter $6-\mathrm{MWD}(401 \pm 100$ vs. $459 \pm 104 \mathrm{~m}, \mathrm{P}<0.001)$, a higher NT-proBNP [903.5 (238.8-2189.3) vs. 112.1 (44.6-234.7), $\mathrm{P}<0.001]$, and a poorer WHO FC $(\mathrm{P}<0.001)$. The echocardiographic and hemodynamic parameters of the two groups were also statistically significantly different. The details are displayed in Table 1.

\section{CPET characteristics of patients with $P H$}

The time interval between CPET and RHC was less than 7 days. No adverse events resulted from performing both of them. Table 2 compares the CPET variables between patients with and without $\mathrm{PH}$. Besides peak VE, peak SBP, peak diastolic blood pressure (DBP), and HRR, the other CPET variables were statistically different. Patients with $\mathrm{PH}$ had decreased exercise tolerance, which was mainly reflected by a significant decrease in peak WR $(72 \pm 30$ vs. $103 \pm 43 \mathrm{~W}, \mathrm{P}<0.001)$, AT $[10.0$ (8.6-12.2) vs. $\left.12.5(10.9-14.3) \mathrm{mL} \cdot \mathrm{kg}^{-1} \cdot \mathrm{min}^{-1}, \mathrm{P}<0.001\right]$, peak $\mathrm{VO}_{2}$ (13.8 \pm 6.0 vs. $\left.18.5 \pm 5.4 \mathrm{~mL} \cdot \mathrm{kg}^{-1} \cdot \mathrm{min}^{-1}, \mathrm{P}<0.001\right)$, and OUES $(1,025.2 \pm 463.0$ vs. $1,539.4 \pm 458.0, \mathrm{P}<0.001)$. $\mathrm{PH}$ patients also showed poor circulatory response, which was supported by significant decreases in peak HR (134 \pm 23 vs. $\left.140 \pm 24 \mathrm{~min}^{-1}, \mathrm{P}=0.038\right), \mathrm{O}_{2}$ pulse $(6.1 \pm 2.1$ vs. $8.5 \pm 2.7 \mathrm{~mL} \cdot \mathrm{min}^{-1} \cdot$ beat $\left.^{-1}, \mathrm{P}<0.001\right)$, and peak circulatory power $[1,776.0(1,341.2-2,293.2)$ vs. $2,447.3(1,833.7-$ $\left.3,251.4) \mathrm{mmHg} \cdot \mathrm{mL}^{-1} \cdot \mathrm{kg}^{-1} \cdot \mathrm{min}^{-1}, \mathrm{P}<0.001\right]$. In addition, ineffective ventilation was increased in $\mathrm{PH}$ patients, which was reflected by significant decreases in $\mathrm{PetCO}_{2}$ at AT $(29 \pm 7$ vs. $38 \pm 7 \mathrm{mmHg}, \mathrm{P}<0.001)$ and peak ventilatory power 
Table 1 Basic characteristics of all participants

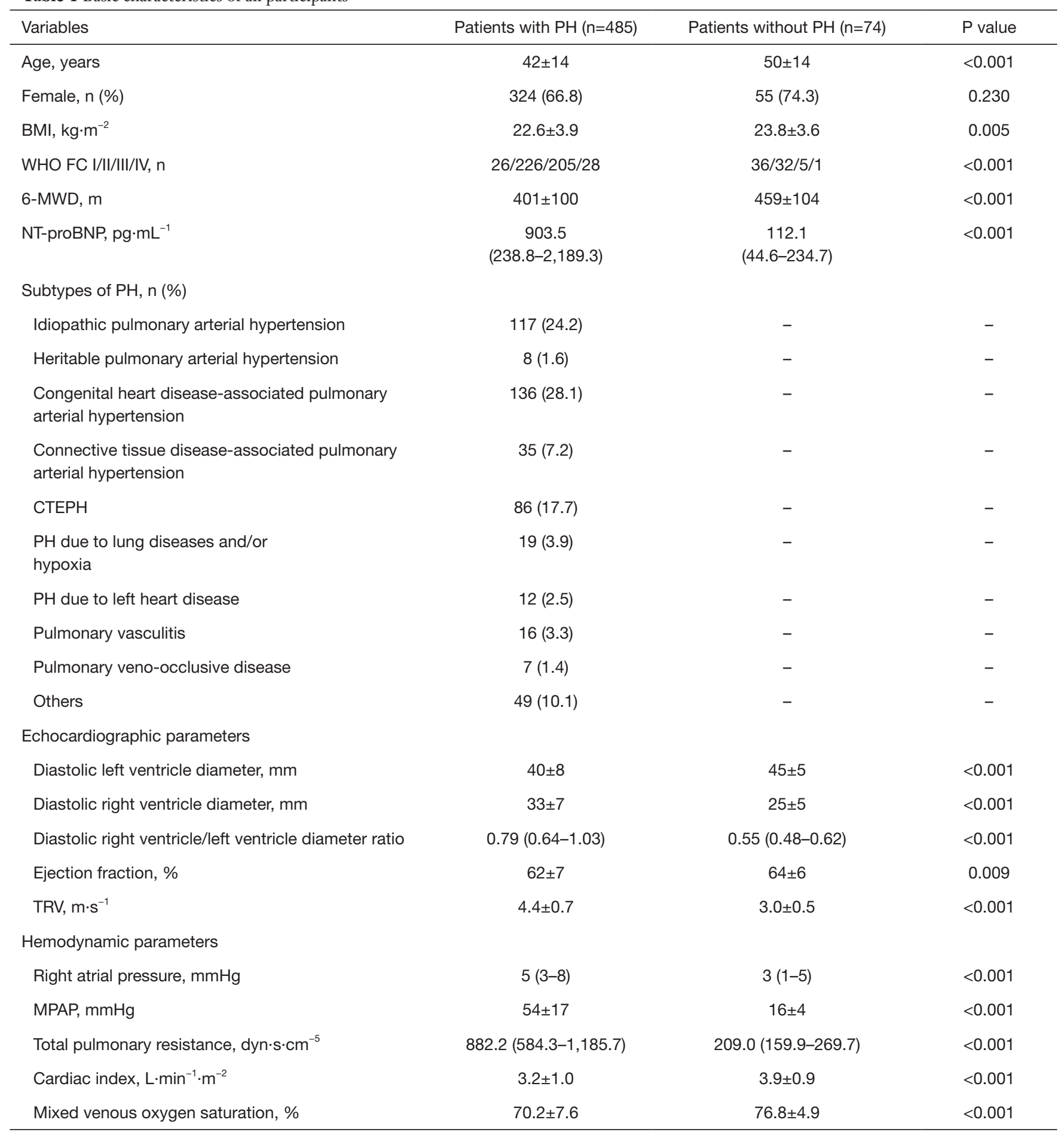

Continuous variables are presented as mean \pm SD or median (interquartile range). Categorical variables are given as counts or percent. $\mathrm{P}<0.05$ represents statistical difference. $\mathrm{PH}$, pulmonary hypertension; BMI, body mass index; WHO FC, World Health Organization functional class; 6-MWD, six minutes walking distance; NT-proBNP, N-terminal pro-brain natriuretic peptide; CTEPH, chronic thromboembolic pulmonary hypertension; TRV, tricuspid regurgitation velocity; MRAP, mean pulmonary arterial pressure. 
Table 2 The characteristics of CPET variables in patients with and without $\mathrm{PH}$

\begin{tabular}{|c|c|c|c|}
\hline Variables & Patients with $\mathrm{PH}(\mathrm{n}=485)$ & Patients without $\mathrm{PH}(\mathrm{n}=74)$ & $P$ value \\
\hline AT, $\mathrm{mL} \cdot \mathrm{kg}^{-1} \cdot \mathrm{min}^{-1}$ & $10.0(8.6-12.2)$ & $12.5(10.9-14.3)$ & $<0.001$ \\
\hline Peak VO${ }_{2}, \mathrm{~mL} \cdot \mathrm{kg}^{-1} \cdot \mathrm{min}^{-1}$ & $13.8 \pm 6.0$ & $18.5 \pm 5.4$ & $<0.001$ \\
\hline Peak RER & $1.09 \pm 0.10$ & $1.14 \pm 0.13$ & $<0.001$ \\
\hline Peak HR, $\min ^{-1}$ & $134 \pm 23$ & $140 \pm 24$ & 0.038 \\
\hline Peak $\mathrm{O}_{2}$ pulse, $\mathrm{mL} \cdot \mathrm{min}^{-1} \cdot$ beat $^{-1}$ & $6.1 \pm 2.1$ & $8.5 \pm 2.7$ & $<0.001$ \\
\hline Peak SBP, mmHg & $136 \pm 31$ & $144 \pm 34$ & 0.056 \\
\hline Peak DBP, mmHg & $86 \pm 24$ & $88 \pm 23$ & 0.468 \\
\hline VE/VCO ${ }_{2}$ slope & $44.0 \pm 18.1$ & $28.6 \pm 7.3$ & $<0.001$ \\
\hline OUES & $1,025.2 \pm 463.0$ & $1,539.4 \pm 458.0$ & $<0.001$ \\
\hline HRR, $\min ^{-1}$ & $28(15-45)$ & $29(21-38)$ & 0.790 \\
\hline $\begin{array}{l}\text { Peak circulatory power, } \\
\mathrm{mmHg} \cdot \mathrm{mL}^{-1} \cdot \mathrm{kg}^{-1} \cdot \mathrm{min}^{-1}\end{array}$ & 1,776.0 (1,341.2-2,293.2) & $2,447.3(1,833.7-3,251.4)$ & $<0.001$ \\
\hline Peak ventilatory power, mmHg & $3.5 \pm 1.6$ & $5.3 \pm 1.9$ & $<0.001$ \\
\hline
\end{tabular}

Continuous variables are presented as mean $\pm \mathrm{SD}$ or median (interquartile range). $\mathrm{P}<0.05$ represents statistical difference. CPET, cardiopulmonary exercise testing; $\mathrm{PH}$, pulmonary hypertension; WR, work rate; AT, anaerobic threshold; $\mathrm{VO}_{2}$, oxygen uptake; $\mathrm{RER}$, respiratory exchange ratio; VE, minute ventilation; HR, heart rate; $\mathrm{O}_{2}$ pulse, oxygen pulse; SBP, systolic blood pressure; DBP, diastolic blood pressure; $P$ etCO $\mathrm{C}_{2}$, end-tidal carbon dioxide partial pressure; $\mathrm{VCO}_{2}$, carbon dioxide output; OUES, oxygen uptake efficiency slope; HRR, heart rate recovery.

(3.5 \pm 1.6 vs. $5.3 \pm 1.9 \mathrm{mmHg}, \mathrm{P}<0.001)$, along with significant increases in $\mathrm{VE} / \mathrm{VCO}_{2}$ at $\mathrm{AT}(43.6 \pm 10.4$ vs. $31.6 \pm 5.7$, $\mathrm{P}<0.001)$ and the $\mathrm{VE} / \mathrm{VCO}_{2}$ slope $(44.0 \pm 18.1$ vs. $28.6 \pm 7.3$, $\mathrm{P}<0.001)$.

\section{CPET variables independently associated with $\mathrm{PH}$}

As shown in Table 3, univariate logistic regression analysis revealed that age, BMI, and CPET variables except for AT and peak $\mathrm{HR}$ were associated with $\mathrm{PH}$ (all $\mathrm{P}<0.001$ ). Age, sex, BMI, peak WR, peak $\mathrm{VO}_{2}$, peak RER, $\mathrm{O}_{2}$ pulse, $\mathrm{PetCO}_{2}$ at $\mathrm{AT}$, the $\mathrm{VE} / \mathrm{VCO}_{2}$ at $\mathrm{AT}, \mathrm{VE} / \mathrm{VCO}_{2}$ slope, peak circulatory power and peak ventilatory power were subsequently included in multivariate logistic regression analysis. After adjustment for age, sex and BMI, CPET variables including peak WR, peak $\mathrm{VO}_{2}$, and $\mathrm{PetCO}_{2}$ at AT were independently associated with $\mathrm{PH}$ (Table 4). In addition, the above three
CPET variables were significantly correlated with the mPAP measured by RHC, the lower the peak WR, peak $\mathrm{VO}_{2}$ and $\mathrm{PetCO}_{2}$ at AT, the higher the mPAP value (Figure 2).

\section{ROC curve analysis of CPET variables in $\mathrm{PH}$ diagnosis}

The ROC curve analysis of CPET variables in the diagnosis of $\mathrm{PH}$ was performed using the gold standard mentioned previously. The sensitivity, specificity, and the area under the receiver operator characteristic curve (AUC) of CPET variables in $\mathrm{PH}$ diagnosis are shown in Table 5. A regression equation was obtained from multivariate ROC curve analysis as follows: $\mathrm{Y}=9.294-0.0048 \times$ peak $\mathrm{WR}-0.0173 \times$ peak $\mathrm{VO}_{2}-0.0752 \times \mathrm{PetCO}_{2}$ at AT. Combining with the above three CPET variables, this model had the highest AUC $[0.890$ (0.852-0.927), $\mathrm{P}<0.001]$ and high sensitivity $(81.8 \%)$ and specificity (86.5\%) for diagnosing $\mathrm{PH}$, as shown in Figure 3. 
Table 3 Factors associated with PH in univariate logistic regression analysis

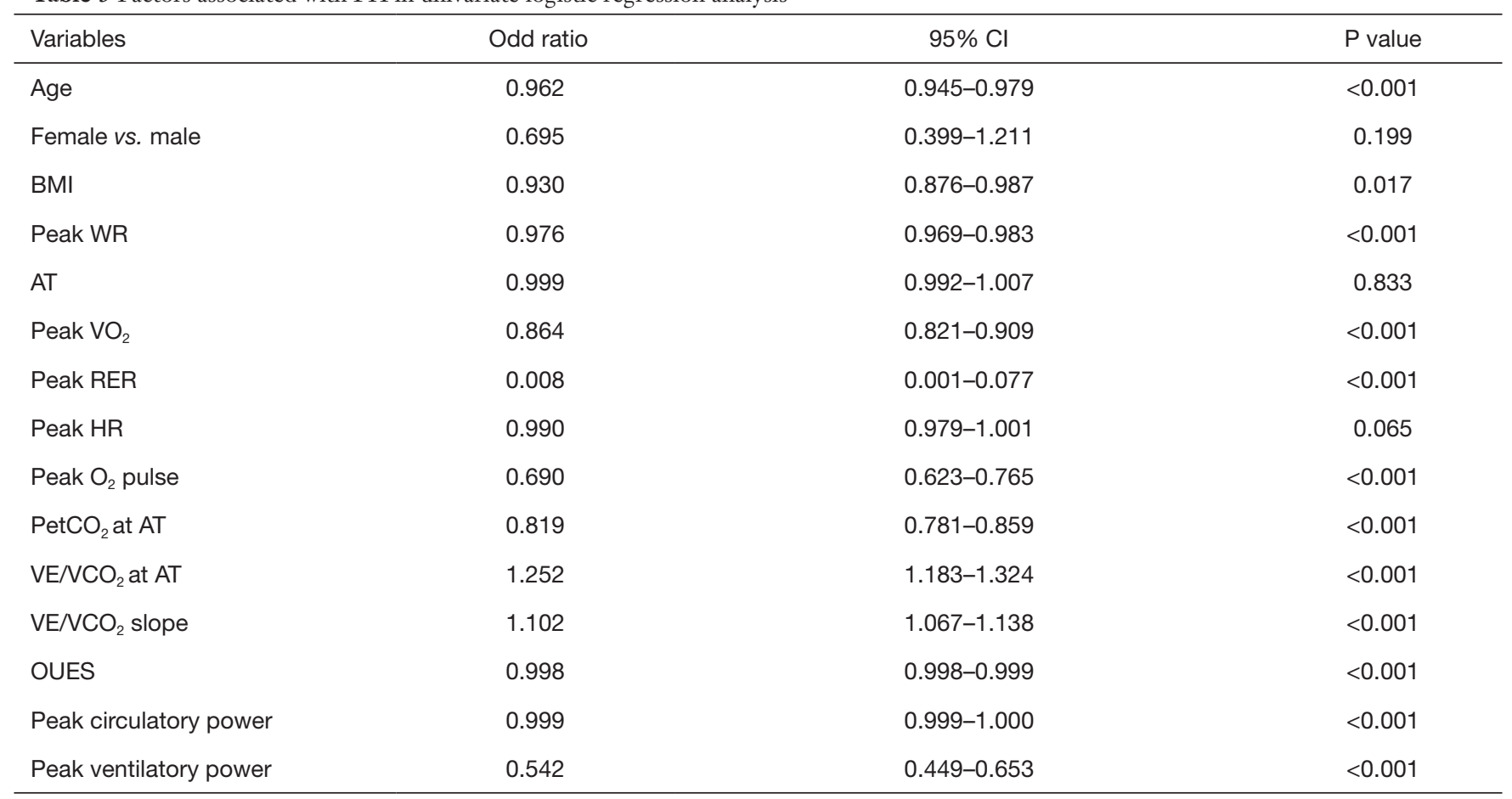

$\mathrm{P}<0.05$ represents statistical difference. $\mathrm{PH}$, pulmonary hypertension; $\mathrm{BMI}$, body mass index; WR, work rate; $\mathrm{AT}$, anaerobic threshold; VO ${ }_{2}$, oxygen uptake; RER, respiratory exchange ratio; $\mathrm{HR}$, heart rate; $\mathrm{O}_{2}$ pulse, oxygen pulse; $\mathrm{PetCO}_{2}$, end-tidal carbon dioxide partial pressure; $\mathrm{VE}$, minute ventilation; $\mathrm{VCO}_{2}$, carbon dioxide output; OUES, oxygen uptake efficiency slope.

Table 4 Multivariate logistic regression analysis after adjustment for age, sex and BMI

\begin{tabular}{lccc}
\hline Variables & Odd ratio & $95 \% \mathrm{Cl}$ & P value \\
\hline Peak WR & 0.973 & $0.961-0.986$ & $<0.001$ \\
Peak VO & 0.949 & $0.910-0.990$ & 0.015 \\
PetCO $_{2}$ at AT & 0.865 & $0.820-0.913$ & $<0.001$ \\
\hline
\end{tabular}

$\mathrm{P}<0.05$ represents statistical difference. $\mathrm{BMI}$, body mass index; $\mathrm{WR}$, work rate; $\mathrm{VO}_{2}$, oxygen uptake; PetCO ${ }_{2}$, end-tidal carbon dioxide partial pressure; AT, anaerobic threshold.

\section{Subgroup analyses of missed diagnosis and misdiagnosis of PH by echocardiography}

Patients with TRV $\leq 2.8 \mathrm{~m} \cdot \mathrm{s}^{-1}$ were not considered to have PH. However, among 59 patients whose TRV $\leq 2.8 \mathrm{~m} \cdot \mathrm{s}^{-1}, 28$ patients were confirmed to have PH by RHC. The cutoff values of CPET variables could identify a subset of patients with normal echocardiography (Table 6). Patients with TRV $>2.8 \mathrm{~m} \cdot \mathrm{s}^{-1}$ together with other echocardiographic signs were considered to have PH. Forty-three patients screened as $\mathrm{PH}$ by echocardiography were confirmed to have a normal
mPAP by RHC. The cutoff values of CPET variables could also identify a subset of patients misdiagnosed as $\mathrm{PH}$ by echocardiography (Table 7).

\section{Discussion}

$\mathrm{PH}$ presents similar lesions like wall thickening and luminal narrowing of the pulmonary arterioles are presented regardless of the specific pathogenetic mechanism (13). This pulmonary vascular remodeling leads to an increase in pulmonary vascular resistance and a corresponding increase 

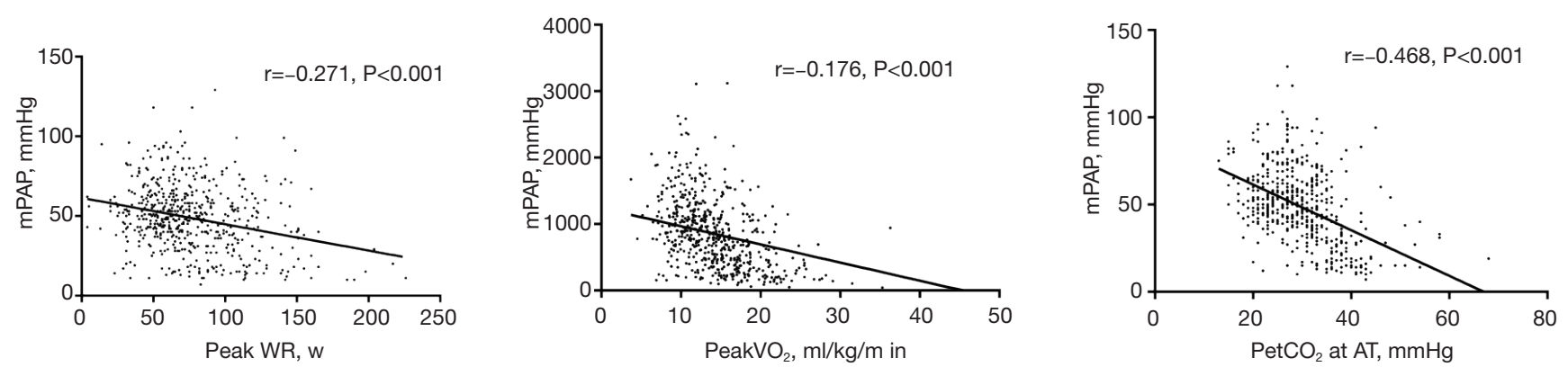

Figure 2 The relationship between CPET variables and mPAP. CPET, cardiopulmonary exercise testing; MPAP, mean pulmonary arterial pressure; $\mathrm{WR}$, work rate; $\mathrm{VO}_{2}$, oxygen uptake; $\mathrm{PetCO}_{2}$, end-tidal carbon dioxide partial pressure; AT, anaerobic threshold.

Table 5 ROC curve analysis for CPET variables in PH diagnosis

\begin{tabular}{lcccc}
\hline Variables & Cutoff value & AUC $(95 \% \mathrm{Cl})$ & Sensitivity/Specificity (\%) & P value \\
\hline Peak WR & 82 & $0.734(0.668-0.799)$ & $70.3 / 68.6$ & $82.4 / 61.4$ \\
PeakVO $_{2}$ & 14.2 & $0.777(0.719-0.835)$ & $80.9 / 86.2$ & $<0.001$ \\
PetCO $_{2}$ at AT & 35 & $0.876(0.830-0.922)$ & $81.8 / 86.5$ & $<0.001$ \\
Combined CPET variables & 0.86 & $0.890(0.852-0.927)$ & $<0.001$ \\
\hline
\end{tabular}

$\mathrm{P}<0.05$ represents statistical difference. $\mathrm{ROC}$, receiver operator characteristic; CPET, cardiopulmonary exercise testing; AUC, area under the receiver operator characteristic curve; WR, work rate; $\mathrm{VO}_{2}$, oxygen uptake; $\mathrm{Pet} \mathrm{CO}_{2}$, end-tidal carbon dioxide partial pressure; AT, anaerobic threshold.
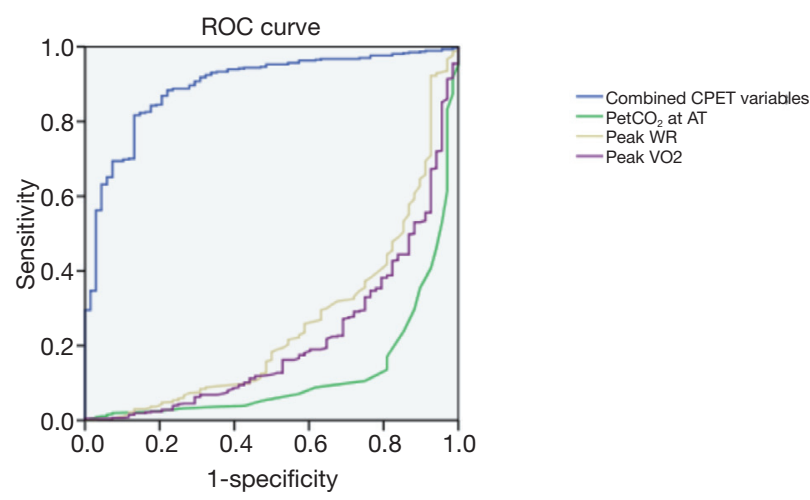

Figure 3 The ROC curve of CPET variables in PH diagnosis. ROC, receiver operator characteristic; CPET, cardiopulmonary exercise testing; WR, work rate; $\mathrm{VO}_{2}$, oxygen uptake; $\mathrm{PetCO}$, end-tidal carbon dioxide partial pressure; AT, anaerobic threshold.

in pulmonary artery pressure. Right heart function becomes impaired by the increased right ventricular afterload, and an enlarged right ventricle causes the interventricular septum to shift leftward, which affects left heart filling. Both conditions affect the patient's cardiac output, thus leading to reduced $\mathrm{VO}_{2}$ (14). In addition, pulmonary vascular lesions cause a pulmonary ventilation/ perfusion mismatch and enlargement of a physiological dead space, thus reducing ventilation efficiency (15). Recent studies have found consistent changes in many CPET variables in patients with $\mathrm{PH}$ (16-18). In our study, $\mathrm{PH}$ patients presented with significantly reduced peak WR, AT, peak $\mathrm{VO}_{2}, \mathrm{O}_{2}$ pulse, and $\mathrm{PetCO}_{2}$ at AT, and significantly increased $\mathrm{VE} / \mathrm{VCO}_{2}$ at $\mathrm{AT}$ and $\mathrm{VE} / \mathrm{VCO}_{2}$ slope, compared to non-PH patients. These findings are consistent with the results of previous studies. The value of novel CPET variables including OUES, peak circulatory power and peak ventilatory power were also investigated in this study. Previous research shows that the OUES is significantly lower in patients with heart failure and is also related to the severity of heart failure (19). Borghi-Silva et al. (20) analyzed the CPET and echocardiographic data of 86 heart failure patients with reduced ejection fraction. They found a peak ventilatory power to be significantly decreased, reflecting the impaired right heart function and pulmonary hemodynamic deteriorations in these patients. Cohen-Solal et al. (21) proposed that, of the many CPET variables, peak circulatory power is the best indicator for predicting adverse clinical outcomes in PH. In this study, we found that the three novel CPET variables were significantly reduced in $\mathrm{PH}$ patients, which supports the previous findings. 
Table 6 The value of CPET variables in identification of PH in patients with normal echocardiography

\begin{tabular}{lcc}
\hline Variables & Cutoff value & Positive (PH), n (\%) \\
\hline Peak WR & $<82$ & $11(39.3)$ \\
Peak VO $_{2}$ & $<14.2$ & $8(28.6)$ \\
PetCO $_{2}$ at AT & $<35$ & $21(75.0)$ \\
Combined CPET variables & $>0.86$ & $19(67.9)$ \\
\hline
\end{tabular}

Categorical variables are given as counts or percent. CPET, cardiopulmonary exercise testing; PH, pulmonary hypertension; WR, work rate; $\mathrm{VO}_{2}$, oxygen uptake; $\mathrm{PetCO}_{2}$, end-tidal carbon dioxide partial pressure; AT, anaerobic threshold.

Table 7 The value of CPET variables in identification of non-PH in patients misdiagnosed by echocardiography

\begin{tabular}{lcc}
\hline Variables & Cutoff value & Positive (non-PH), n (\%) \\
\hline Peak WR & $\geq 82$ & $31(72.1)$ \\
Peak VO$_{2}$ & $\geq 14.2$ & $35(81.4)$ \\
PetCO $_{2}$ at AT & $\geq 35$ & $29(67.4)$ \\
Combined CPET variables & $\leq 0.86$ & $36(83.7)$ \\
\hline
\end{tabular}

Categorical variables are given as counts or percent. CPET, cardiopulmonary exercise testing; PH, pulmonary hypertension; WR, work rate; $\mathrm{VO}_{2}$, oxygen uptake; $\mathrm{PetCO}_{2}$, end-tidal carbon dioxide partial pressure; AT, anaerobic threshold.

In a 2010 review published by Arena et al. (22), 19 studies described the reliability of CPET in identifying pulmonary vasculopathy, and its value in diagnosing different $\mathrm{PH}$ subtypes. Several studies have demonstrated a significant correlation between CPET variables and hemodynamic parameters. Yasunobu et al. (23) found that in $\mathrm{PH}$ patients, $\mathrm{PetCO}_{2}$ at rest, at AT and at peak exercise was negatively correlated with mPAP (all $\mathrm{P}<0.05)$. An article published by Holverda et al. (24) indicated that the lowest $\mathrm{VE} / \mathrm{VCO}_{2}$ was significantly correlated with $\mathrm{mPAP}(\mathrm{r}=0.43, \mathrm{P}<0.05)$. Gläser et al. (25) investigated patients with pulmonary fibrosis and found that the $\mathrm{VE} / \mathrm{VCO}_{2}$ slope $(\mathrm{r}=0.77, \mathrm{P}<0.05)$ and peak $\mathrm{VO}_{2}(\mathrm{r}=-0.52, \mathrm{P}<0.05)$ was significantly correlated with pulmonary artery systolic pressure in patients who had pulmonary arterial hypertension due to pulmonary fibrosis. As above, our study also found that peak WR, peak $\mathrm{VO}_{2}$, peak RER, peak $\mathrm{O}_{2}$ pulse, $\mathrm{PetCO}_{2}$ at AT, OUES, peak circulatory power, and peak ventilatory power were negatively correlated with $\mathrm{mPAP}$ in all included patients with suspected $\mathrm{PH}$, while $\mathrm{VE} / \mathrm{VCO}_{2}$ at $\mathrm{AT}$ and the $\mathrm{VE} /$ $\mathrm{VCO}_{2}$ slope were positively correlated with mPAP (data not shown). Of these, peak WR, peak $\mathrm{VO}_{2}$ and PetCO2 at AT were founded to be independently associated with PH. A study conducted by Zhao et al. (26) included 88 patients with echocardiography-suspected $\mathrm{PH}$. The results showed that the combination of the $\mathrm{VE} / \mathrm{VCO}_{2}$ slope and
AT achieved a sensitivity and specificity of $93 \%$ and $95 \%$, respectively, for diagnosing $\mathrm{PH}$ with $\mathrm{RHC}$ used as the gold standard. In our study, the combination of the CPET variables including peak $W R$, peak $\mathrm{VO}_{2}$, and $\mathrm{PetCO}_{2}$ at $\mathrm{AT}$ also had high sensitivity and specificity in $\mathrm{PH}$ diagnosis.

Sciumè et al. (27) conducted a follow-up study in patients with primary myelofibrosis and found that patients with normal baseline echocardiography but abnormal CPET developed PH after 12 months of follow-up. Their results demonstrated that CPET was more sensitive and specific than echocardiography in the identification of pulmonary vascular lesions. In the present study, the regression equation $\mathrm{Y}=9.294-0.0048 \times$ peak $\mathrm{WR}-0.0173 \times$ peak $\mathrm{VO}_{2}-0.0752$ $\times \mathrm{PetCO}_{2}$ at AT achieved the highest AUC, which showed improved sensitivity and specificity in diagnosing $\mathrm{PH}$. When $\mathrm{Y}$ was $>0.86$, it supported the $\mathrm{PH}$ diagnosis. We conducted subgroup analyses of patients who had a missed diagnosis or misdiagnosis $\mathrm{PH}$ by echocardiography. The cutoff value ( $\mathrm{Y}>0.86)$ of the combined CPET variables including peak WR, peak $\mathrm{VO}_{2}$, and $\mathrm{PetCO}_{2}$ identified 19 out of 28 patients who had a normal echocardiography but who were confirmed as $\mathrm{PH}$ by RHC. However, the cutoff value $(\mathrm{Y} \leq 0.86)$ identified 36 out of 49 non-PH patients who were misdiagnosed as $\mathrm{PH}$ by echocardiography. Therefore, the negative predictive value of the combined CPET variables for $\mathrm{PH}$ diagnosis is higher. This shows that CPET is able to identify patients 
who are misdiagnosed as $\mathrm{PH}$ by echocardiography, and these patients can therefore be spared from invasive RHC, thus reducing the psychological and financial burden on patients and their families.

\section{Limitations}

One significant limitation of the study is the use of sample with suspected PH. Thus, the identified CPET parameters may be more valuable for the identification of $\mathrm{PH}$ from suspected $\mathrm{PH}$. Patients with $\mathrm{PH}$ in our study had many subtypes due to different etiologies, the degree of $\mathrm{VO}_{2}$ decline and the severity of pulmonary ventilation/ perfusion mismatch might vary. But the PH patients' number in different subtypes had a big difference. Thus, subgroup analyses were not conducted. In future prospective study, the diagnostic value of CPET in each subtype of $\mathrm{PH}$ will be explored respectively. In addition, our study investigated only the commonly used clinical CPET variables. The other significant limitation is no external validation sample for testing the external validity of CPET. The accuracy of CPET cutoff values for $\mathrm{PH}$ diagnosis needs to be validated in multiple centers.

The authors may consider subgroup analyses according to subtypes of $\mathrm{PH}$. The diagnostic value for $\mathrm{PH}$ subtypes is also interesting.

\section{Conclusions}

CPET has significant value as a non-invasive method for the diagnosis of PH. Together with echocardiography, it can reduce the rates of missed diagnosis and misdiagnosis in patients with suspected $\mathrm{PH}$, thus helping clinicians to accurately predict diagnosis and formulate appropriate treatment plans.

\section{Acknowledgments}

Funding: This work was supported by Beijing Municipal Science and Technology Project [grant number Z181100001718200].

\section{Footnote}

Reporting Checklist: The authors have completed the STARD reporting checklist. Available at http://dx.doi.org/10.21037/ jtd-20-1061b

Data Sharing Statement: Available at http://dx.doi. org/10.21037/jtd-20-1061b
Conflicts of Interest: All authors have completed the ICMJE uniform disclosure form (available at http://dx.doi. org/10.21037/jtd-20-1061b). The authors have no conflicts of interest to declare.

Ethical Statement: The authors are accountable for all aspects of the work in ensuring that questions related to the accuracy or integrity of any part of the work are appropriately investigated and resolved. The study was conducted in accordance with the Declaration of Helsinki (as revised in 2013). The study was approved by committee board of the Fuwai Hospital (NO.: 2018-BKJ09) and informed consent was taken from all the patients.

Open Access Statement: This is an Open Access article distributed in accordance with the Creative Commons Attribution-NonCommercial-NoDerivs 4.0 International License (CC BY-NC-ND 4.0), which permits the noncommercial replication and distribution of the article with the strict proviso that no changes or edits are made and the original work is properly cited (including links to both the formal publication through the relevant DOI and the license). See: https://creativecommons.org/licenses/by-nc-nd/4.0/.

\section{References}

1. Archer SL, Weir EK, Wilkins MR. Basic science of pulmonary arterial hypertension for clinicians: new concepts and experimental therapies. Circulation 2010;121:2045-66.

2. Deaño RC, Glassner-Kolmin C, Rubenfire M, et al. Referral of patients with pulmonary hypertension diagnoses to tertiary pulmonary hypertension centers: the multicenter RePHerral study. JAMA Intern Med 2013;173:887-93.

3. Maron BA, Choudhary G, Khan UA, et al. Clinical profile and underdiagnosis of pulmonary hypertension in US veteran patients. Circ Heart Fail 2013;6:906-12.

4. Fisher MR, Forfia PR, Chamera E, et al. Accuracy of Doppler echocardiography in the hemodynamic assessment of pulmonary hypertension. Am J Respir Crit Care Med 2009;179:615-21.

5. Held M, Grun M, Holl R, et al. Cardiopulmonary exercise testing to detect chronic thromboembolic pulmonary hypertension in patients with normal echocardiography. Respiration 2014;87:379-87.

6. Galiè N, Humbert M, Vachiery JL, et al. 2015 ESC/ERS 
Guidelines for the Diagnosis and Treatment of Pulmonary Hypertension. Rev Esp Cardiol (Engl Ed) 2016;69:177.

7. Woods PR, Frantz RP, Taylor BJ, et al. The usefulness of submaximal exercise gas exchange to define pulmonary arterial hypertension. J Heart Lung Transplant 2011;30:1133-42.

8. Nishio R, Tanaka H, Tsuboi Y, et al. Differences in hemodynamic parameters and exercise capacity between patients with pulmonary arterial hypertension and chronic heart failure. J Cardiopulm Rehabil Prev 2012;32:379-85.

9. Thirapatarapong W, Armstrong HF, Bartels MN. Comparing cardiopulmonary exercise testing in severe COPD patients with and without pulmonary hypertension. Heart Lung Circ 2014;23:833-40.

10. Rudski LG, Lai WW, Afilalo J, et al. Guidelines for the echocardiographic assessment of the right heart in adults: a report from the American Society of Echocardiography endorsed by the European Association of Echocardiography, a registered branch of the European Society of Cardiology, and the Canadian Society of Echocardiography. J Am Soc Echocardiogr 2010;23:685713; quiz 786-688.

11. Hoeper MM, Bogaard HJ, Condliffe R, et al. Definitions and diagnosis of pulmonary hypertension. J Am Coll Cardiol 2013;62:D42-50.

12. Guazzi M, Arena R, Halle M, et al. 2016 focused update: clinical recommendations for cardiopulmonary exercise testing data assessment in specific patient populations. Eur Heart J 2018;39:1144-61.

13. Vonk Noordegraaf A, Groeneveldt JA, Bogaard HJ. Pulmonary hypertension. Eur Respir Rev 2016;25:4-11.

14. Chatterjee NA, Murphy RM, Malhotra R, et al. Prolonged mean $\mathrm{VO} 2$ response time in systolic heart failure: an indicator of impaired right ventricular-pulmonary vascular function. Circ Heart Fail 2013;6:499-507.

15. Guazzi M, Bandera F, Ozemek C, et al. Cardiopulmonary Exercise Testing: What Is its Value? J Am Coll Cardiol 2017;70:1618-36.

16. Farina S, Correale M, Bruno N, et al. The role of cardiopulmonary exercise tests in pulmonary arterial hypertension. Eur Respir Rev 2018;27:170134.

Cite this article as: Luo Q, Yu X, Zhao Z, Zhao Q, Ma X, Jin Q, Yan L, Zhang Y, Liu Z. The value of cardiopulmonary exercise testing in the diagnosis of pulmonary hypertension. J Thorac Dis 2021;13(1):178-188. doi: 10.21037/jtd-20-1061b
17. Paolillo S, Farina S, Bussotti M, et al. Exercise testing in the clinical management of patients affected by pulmonary arterial hypertension. Eur J Prev Cardiol 2012;19:960-71.

18. Weatherald J, Farina S, Bruno N, et al. Cardiopulmonary Exercise Testing in Pulmonary Hypertension. Ann Am Thorac Soc 2017;14:S84-92.

19. Van Laethem C, Bartunek J, Goethals M, et al. Oxygen uptake efficiency slope, a new submaximal parameter in evaluating exercise capacity in chronic heart failure patients. Am Heart J 2005;149:175-80.

20. Borghi-Silva A, Labate V, Arena R, et al. Exercise ventilatory power in heart failure patients: functional phenotypes definition by combining cardiopulmonary exercise testing with stress echocardiography. Int J Cardiol 2014;176:1348-9.

21. Cohen-Solal A, Tabet JY, Logeart D, et al. A non-invasively determined surrogate of cardiac power ('circulatory power') at peak exercise is a powerful prognostic factor in chronic heart failure. Eur Heart J 2002;23:806-14.

22. Arena R, Lavie CJ, Milani RV, et al. Cardiopulmonary exercise testing in patients with pulmonary arterial hypertension: an evidence-based review. J Heart Lung Transplant 2010;29:159-73.

23. Yasunobu Y, Oudiz RJ, Sun XG, et al. End-tidal PCO2 abnormality and exercise limitation in patients with primary pulmonary hypertension. Chest 2005;127:1637-46.

24. Holverda S, Bogaard HJ, Groepenhoff H, et al. Cardiopulmonary exercise test characteristics in patients with chronic obstructive pulmonary disease and associated pulmonary hypertension. Respiration 2008;76:160-7.

25. Gläser S, Noga O, Koch B, et al. Impact of pulmonary hypertension on gas exchange and exercise capacity in patients with pulmonary fibrosis. Respir Med 2009;103:317-24.

26. Zhao QH, Wang L, Pudasaini B, et al. Cardiopulmonary exercise testing improves diagnostic specificity in patients with echocardiography-suspected pulmonary hypertension. Clin Cardiol 2017;40:95-101.

27. Sciumè M, Mattiello V, Cattaneo D, et al. Early detection of pulmonary hypertension in primary myelofibrosis: The role of echocardiography, cardiopulmonary exercise testing, and biomarkers. Am J Hematol 2017;92:E47-8. 